American J. of Engineering and Applied Sciences 4 (1): 93-101, 2011

ISSN 1941-7020

(C) 2010 Science Publications

\title{
Performance of IBS Precast Concrete Beam-Column Connections Under Earthquake Effects: A Literature Review
}

\author{
Patrick Tiong Liq Yee, Azlan Bin Adnan, \\ Abdul Karim Mirasa and Ahmad Baharuddin Abdul Rahman \\ Department of Structures and Materials, Faculty of Civil Engineering, \\ University Technology Malaysia, Malaysia
}

\begin{abstract}
Problem statement: Despite demonstrating rather much benefits comparing to the conventional cast-in-place construction, the acceptance level of precast concrete building is still reportedly low in Malaysia. The implication imposed by stricter seismic design provisions would only worsen the matter. Approach: The main objective of this study was to identify the most appropriate type of beam-column connections to be introduced to precast concrete industry, particularly for regions of low to moderate seismicity. Hence, this study presented a comprehensive literature overview of the findings from studies conducted to analyze and investigate the behavior of precast concrete systems assembled with typical connections or joints under simulated earthquake loading. Results: The seismic performance of precast concrete structure very much depended on the ductility capacity of the connectors jointing each precast components, especially at critical joints such as the beam-to-column connections. It was learnt from the review that (1) hybrid post-tensioned beam-column connection and (2) Dywidag Ductile Connector ${ }^{\circledR}$ were among the most widely used connectors for precast construction in seismic prone regions. Conclusion: Future refinement and research could be carried out in order to optimize these connections to be used in low seismicity regions. Proposed connection type should be practical and well-accepted to avoid further impediment of the precast system.
\end{abstract}

Key words: Beam-column connections, precast frame, precast connection, IBS precast concrete

\section{INTRODUCTION}

The term 'Industrialized Building System' (IBS) refers to a construction method of a building or other structure where its structural components are either wholly or partly being prefabricated as well as manufactured off-site for assembling and installation at building sites. Prefabricated steel structures such as hotrolled steel beams, columns or trusses and precast concrete elements are among some of the popular IBS products. Steel structures are relatively lighter in mass and lacking in stiffness, but having higher overall cost. Besides that, expensive metal cladding systems are required in order to enhance durability and meeting architectural demands. Precast concrete structures, on the other hand had seems to be more practical, especially with the prices of steel which is getting rather unstable nowadays.

The introduction of precast concrete structural systems has, over the years, shown advantages in concrete structure constructions such as improved quality control, easier management of construction schedule, efficient use of materials and cost saving
(Megally et al., 2002). The conventional wet cast insitu constructions, which relatively require more construction space at sites, labor, longer pending time for concrete curing and hardening process and poorer quality control had seems to be replaced at a slow pace, but at a wide scale by the precast concrete systems.

Some examples of the challenging but great, completed precast concrete structures are the Olympic Stadium (Zhenqiang and Ramirez, 1998) in San Pedro Sula, Honduras which was completed in November 1997 and the B.C. Rail Yard Control Tower (Gerald, 1998) in British Columbia, completed in February 1995. The construction of the 40,000 seating capacity Olympic Stadium together with 250 skyboxes used an all precast/prestressed concrete system. More than 7000 pieces of multi-varieties precast components were used as the stadium's construction materials, including the primary beams and columns. Meanwhile, the precast design for the $15.2 \mathrm{~m}$ height control tower took into account the high seismic activities in the region. Henceforth, the vertically stacked precast segments were joined by lapping of the vertical reinforcement bars posted-installed in grouted ducts to cater for the 
high seismic forces. Figure 1 illustrates the image of a popular precast concrete frame erected shopping complex in Johor Bahru with while Fig. 2 reflects its typical beamcolumn connection. Figure 3 shows another precast structure in the state of Kedah, Malaysia.

Background: Compared to conventional cast-in-situ reinforced concrete constructions, precast concrete methods have shown significant advantages such as:

- Depending on the investment at precast plant or factory and the nature of the projects, the usage of precast concrete will usually lower the overall construction cost especially through material costs saving in formwork and shutters fabrications for large projects. The costs for formwork and scaffolding in cast-in-situ reinforced concrete constructions could be as high as one third of the overall project costs. The moulds and formwork used for prefabrication of precast concrete components at precast plants are properly designed to be made from plastic-timber or metal which if properly used can last up to more than hundreds of casting cycles

- The casting and curing of precast concrete elements in shuttered factory under controlled environment and conditions have ruled out the influence of bad weather in disturbing work progress. Besides, the controlled environment and application of most appropriate curing method will improve concrete hardening progress as well as produce higher quality products

- The mass production of standardized precast concrete components has optimized the labors' skill and cost, hence increasing the productivity

- Lesser wet works are required to be carried out at sites with the reducing in the usage of in-situ concrete, mortar or grout, hence making the sites cleaner and dryer. Only some simpler wet works such as mortar plastering or grouting are required when jointing the precast elements, comparing to the pouring of tons of wet concrete slurry in the cast-in-situ works

- An actual case study and analysis comparing the design of a block of flats between the in-situ monolithic building method and the precast unit construction had concluded that the precast unit construction would require only 954 tons of materials comparing to the 2468 tons required in monolithic construction, which meant the precast unit was able to save up to $70 \%$ of material wastages (Glover, 1964). In a separate study, Begum et al., (2010) revealed that prefabrication construction method could reduce tremendously the volume of material wastages compared to conventional building technique.

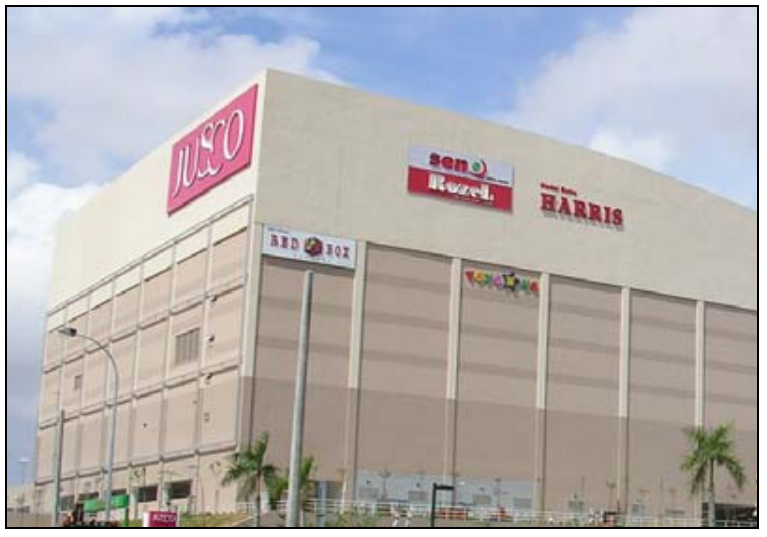

Fig. 1: Precast concrete structure-AEON Jusco Tebrau City, Tebrau, Johor Bahru

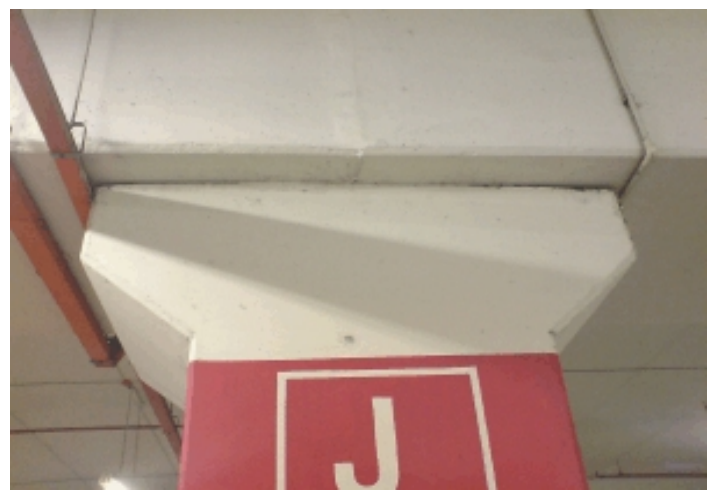

Fig. 2: Finishes of beam-column connection for the shopping complex

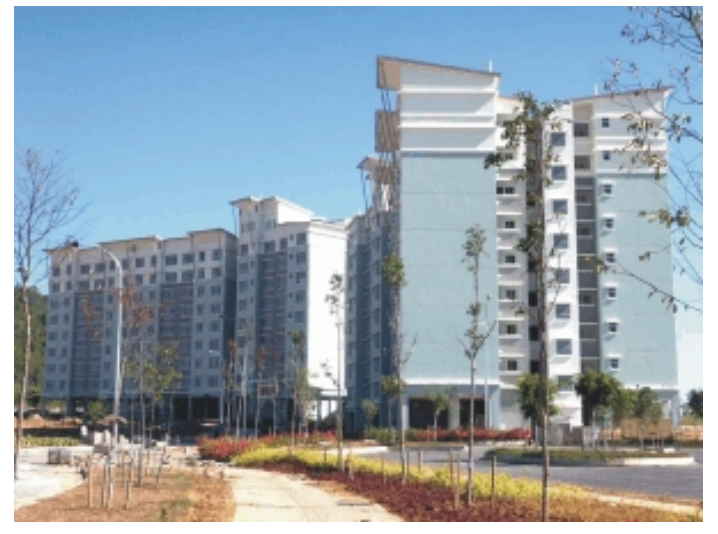

Fig. 3: Precast concrete structure-AIMST, Kedah

\section{MATERIALS AND METHODS}

The key procedure in the conventional cast-in-situ construction is the hectic and costly formwork 
fabricating at site to hold the concrete slurry in designated location as well as to mould and shape them into designated structure shapes. In some large projects, the cost of the formwork and temporary staging or scaffolding could be as high as one third of the project bidding price (Glover, 1964). Besides cost issue, the need of formwork for casting works has limited the architectural design of cast-in-place structures as well.

Precast concrete construction, on the other way round, demonstrates the advantages which is unable to be met by the cast-in-situ method. The Olympic Stadium project in Honduras will be one of a good example. During the tender, four design options were offered including cast-in-situ concrete, precast concrete and structural steel systems, with each design option having their own structural grid patterns. Finally, the cost analysis had concluded that a totally precast/prestressed concrete structural system would be the most efficient and economical proposal, about 30\% cheaper than the other three proposals. Utilizing more than 7000 precast components including single columns, 'A'-shaped frames, ' $\mathrm{H}$ '-shaped frames, single risers, beams, double tees and skyboxes, the material wastage was brought down to minimum (Zhenqiang and Ramirez, 1998). Due to the facts that all these precast components were well-casted and cured at factories, lesser wet works were required at construction site. Only by transporting the necessary precast components on schedule to site, had them assembled and jointed, the construction schedule could be much faster and easier to be managed and controlled. Once the precast components were put in place, dead load and life load testing were carried out immediately to verify the design loading assumptions.

In the conventional cast-in-situ construction, the structural continuity is inbuilt and will mechanically follows as the construction proceeds. Dissimilar to the conventional monolithic concrete structures, the site erection works of precast concrete structures involves of assembling, connecting and jointing numerous pieces of discontinued and discrete precast concrete panels to form either the structure frame systems, or panel of walls. It becomes essential to take into account of the structural continuity that is created needs to be adequate enough for providing the required strength when the precast components are assembled. The connections act as the bridging links between the components. Therefore, it is significant that connections play a very important role in the structural behavior of structures (Sadrnejad and Labibzadeh, 2006). In the construction of the Olympic Stadium, the connections between the individual precast components in the structure frames were built by welding of the protruded, fully anchored reinforcement bars between the joining members. Upon completion of welding, Grade 55 concrete was poured around the joints to embed the welded reinforcement.

Another worth mentioning precast concrete project is the erection of a rail yard control tower in North Vancouver, British Columbia as presented in PCI Journal by Gerald (Gerald, 1998). The design and construction of the tower faced challenges in several aspects including high seismic activities, poor soil condition, possible vibration from nearby rail yard operations, high architectural demand and was bound to tight construction time as well as limited budget. The initial preliminary design called for a structural steel option which was later eliminated due to its relatively lower mass and stiffness besides being more expensive. Cast-in-situ concrete construction option was also being considered. The method was later being ruled out because of the difficulty to achieve the elegant architecture finish. So towards the end, the precast concrete systems were selected, which was not only economical, but at the same time were able to produce durable, stiff structures and most importantly meeting the tight architectural control.

The site erection method of the tower was like stacking Lego toys. Nine pieces of steel-formed hollow precast concrete segments were stacked on top of each other to form the tower elevator shaft. These segments were bonded together vertically by post-installed mild steel reinforcing bars placed in grouted ducts. Stiff mortar was applied at each interface between the segments to increase the bonding strength. Due to the fact that the tower is located in seismic zone (equivalent to California Zone 3), the joint must be able to sustain seismic loading besides adequate in providing monolithic loading resistance. One of the reasons to use mild steel reinforcing bars instead of post-tensioned steels was to resist structure overturning forces. Mild steel reinforcements are more ductile and produce a better structure response under earthquake effects.

Beam-Column connections: The beam-column connection is one of the few vital factors determining the seismic resistance efficiency of a framed or partially-framed structure (Yalciner and Hedayat, 2010). Although properly-designed and fitlyconstructed reinforced concrete structures are no doubt suitable for most earthquake areas, to achieve these two fundamental criteria is a challenge to engineers and builders. Here is where the critical problem arises. A good design must not only be able to withstand the required loadings, but also must be practical and possible to construct. Hence, in the conventional castin-situ reinforced concrete framed structures 
construction, the occurrence of reinforcement congestion at beam-column joints to achieve higher yielding strength has remained a continuous problem in the detailing of beam-column joints to endure tough cyclic loading.

The connection between the beam and column must be strong enough as it serves as part of the vertical load carrying system in order to comply with one of the failure mode principles in which the beams must fail before columns. Under earthquake loading, the joint will be the most critical area to resist the lateral seismic reaction forces (Suyamburaja and Subramanian, 2008). Its characteristics affect the global behavior of the whole structure, particularly when subjected to seismic loading(Ebrahimi et al., 2010). Therefore, the strength of the joint has to be higher than the strength of the member it joins. This makes the proper reinforcement of this zone is difficult to construct and not fully established. Taking for example, the design requirements as stated in the provisions of ACI 318-77 seemed to be inadequate. The designed joint failed in shear and the beam bars slipped only after the first cycle of inelastic loading. Since then, it evolved much difference development of national design codes, which made the uniformity of the design criteria worsen. A collaborated study held between the US, Japan, New Zealand and China regarding the beam-column joints is hoped can eliminate the differences in multiple national code provisions (David, 1987).

Apart from that, with respect to the earthquake and tremor incidents which are seemingly to be occurring more and more frequently, most of the designers and engineers started to doubt the capability and stability of the precast concrete structures in resisting seismicloading. More stringent codes and rules were being introduced by most authorities in protecting the safeties of the public's, such as the ACI 318 building code requirements for structural concrete, 2000 NEHRP provisions and AASHTO guide specification for design and construction of segmental bridges. These design procedures were intended for information and trial design because of limited existing information and knowledge were available (Ghosh, 2001). Most of the people have the common misconception that precast concrete structures are incapable to provide adequate seismic resistance until recent improvements in research development have introduced efficient precast structural systems that are capable of maintaining structural integrity under cyclic loading, among which are the hybrid frame and unbonded jointed precast walls (Priestley et al., 1999).

The efforts in research and development of precast concrete system were lacking even in the late 90's. An international survey which was carried out in 1996-97 on behalf of the FIP Commission on Prefabrication had revealed that the amount of intended future development for precast structures was less than 1 out of 30th as compared to researches in structural steelwork (Elliot et al., 1998). Before this millennium, most of the beam-column joints were designed as pinned connections. Due to the lack of reliable testing data and results, the designers had no choice but to neglect the presence of flexural stresses at the joints. This led to material wastage and uneconomical design of columns and foundations.

\section{RESULTS AND DISCUSSION}

Some of the relevant past researches regarding the precast concrete beam-column connections under seismic loading were presented below.

Welded plate and billet connection: Since 1990, some 24 tests (Elliot et al., 1998) had been conducted to investigate the reliability of welded plate and billet connectors. Figure 4 illustrates the main typical components of a billet connector. These two types connectors are among the most commonly applied construction methods during the time as they are the socalled hidden connectors where the jointing are fully being embedded within the beam and column members. The connectors were concluded to contribute to the semi-rigid behavior of the jointed precast structures. Unfortunately, the testing did not cater for seismic effects.

HPFRC composite connection: The development of an improved design and construction method for precast concrete frames in high seismic areas was conducted at the University of Michigan under the joint research program from the National Science Foundation (NSF)-Precast Seismic Structural Systems (PRESSS). NSF and Precast/Prestressed Concrete Institute (PCI) co-sponsored the research study. The studies on the beam-column connections had led to the founding of a type of Cast-In-Place (CIP) fiber reinforced concrete connections.

The connection requires the fabrication of the precast beams and columns with protruding steel bars at their ends. During construction, the beams would be erected and temporary supported on scaffolding, while casting the connection in place together with its reinforcement cage. The connection was cast by either using high fiber content Fiber Reinforced Concrete (FRC) or Slurry Infiltrated Fiber Concrete (SIFCON) and was designed to dissipate reaction energy between 
Am. J. Engg. \& Applied Sci., 4 (1): 93-101, 2011

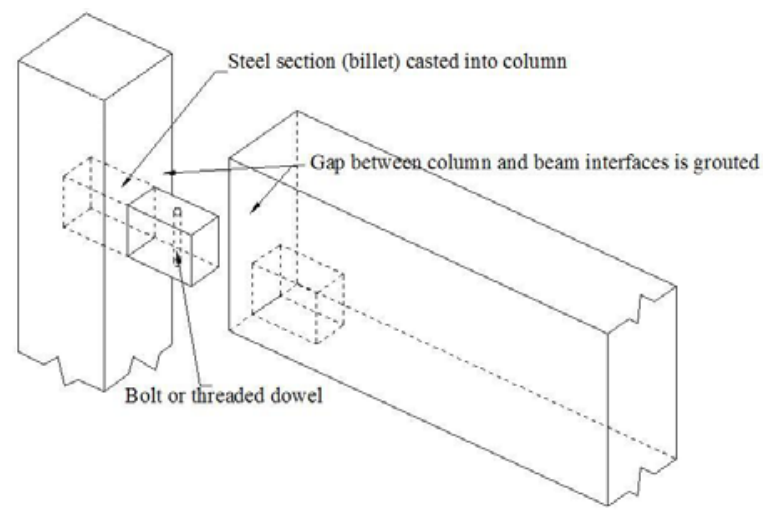

Fig. 4: Billet as beam-column connector

the beam and column members under dynamic loading. Previous research has proved the assimilation of fiber reinforced concrete in the CIP connectors had produced more ductile, increased energy absorption, reduced and better shears resistance connections during earthquake movements, besides reducing the complexity of joint reinforcement in the conventional design. Extended research carried out had improved the connector by introducing a new design scheme.

The CIP High Performance Fiber Reinforcement Cement Composite (HPFRC) connection successfully acts as a plastic hinge by spreading yielding from the center of the connection to the interfaces. This nature of the joint had increased the strength and stiffness of the column by relocating the beam plastic hinge zone away from the column interface. The utilization of steel fiber reinforced concrete in the connections has led to increased energy dissipation capability of up to $350 \%$ over previous normal reinforced concrete connections. At the same time, the increment of strength was reported up to $30 \%$, displacement and rotation resistance up to 65 and $85 \%$ respectively while shear deformation was decreased up to $30 \%$ (Vasconez et al., 1998).

Hybrid post-tensioning frame connection: The third phase of the PRESSS research program was remarkable. The test called for a $60 \%$ scaled prototype of five storey precast/prestressed concrete building to be tested under simulated earthquake loads that represent earthquakes up to 50\% stronger than Zone 4 design levels in codes (Suzanne et al., 1999). The prototype building is designed and constructed to at one shot test and verify four types of different seismic frame systems, besides shear wall and other flooring systems. The main objective of the test was to develop a new set of consistent design guidelines and

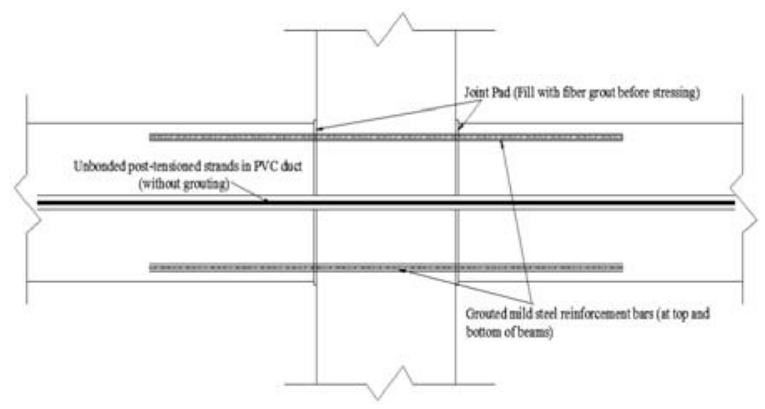

Fig. 5: Hybrid post-tensioning frame (interior jointtypical reinforcement bars are not shown for clarity)

recommendations for jointed precast systems to be incorporated into the existing code provisions thus providing new codifications to update the previous ones. The four different types of seismic connections being tested in the shake test were the TensionCompression Yielding (TCY) gap connection, TCY connection, hybrid connection and pretensioned connection with each of the connections having their own respective energy dissipation capacity and residual displacement control.

The hybrid frame as illustrated in Fig. 5, consisted of beams connected to multi storey columns by both grouted mild steel reinforcement bars (at top and bottom of beam through the column) and unbounded post-tensioned strands running through the center of the beam and passing through the column in a duct. The post-tensioning strands act as ductile connector which will re-center the frame after the shakings. In the PRESSS test, the performance of the hybrid precast concrete frame was extremely good. After more than two cycles of the design level drifts from the cyclic loading tests, the hybrid frame showed only minor of the concrete cover, together with a little bit of crushing besides early failures in the fiber grout pads interfacing the columns and beams. There was no significant development of large shear cracks at the joints (Priestley et al., 1999). This proved that the amount of shear reinforcement provided in the joint as specified in the codes could be reduced. In other related research by Ozden and Ertas (2007), it was found out that the optimum amount of mild steel reinforcement that would best satisfied the connection's flexural capacity would be $20-30 \%$.

With more and more researches regarding the precast hybrid frame being carried out, without any doubt, the system is meeting the requirements of facing seismic challenges. With the new design approved for use in western regional codes for construction in regions of high seismic activity, the hybrid precast frame had made its mark. Since then, hybrid precast 
Am. J. Engg. \& Applied Sci., 4 (1): 93-101, 2011

frames had become one of the typical setups for connections of beam-column in precast construction. Nevertheless, the assembly and jointing of hybrid frame were not easy and straightforward.

Precast RC connections: The lab experimental test by Manoj et al. (2005) had revealed the cyclic performance of reinforced concrete connections influenced by reinforcement anchorage types and length which determines the connectivity of the precast beam and column. Cyclic loads were applied on 4 prototypes; 2 monolithic beam-column structures and the other 2 precast beam and columns members jointed with different reinforcement anchorage and lapping. The monolithic prototypes acted as control experiment corresponding to the similar reinforcement detailing precast prototypes. The first set of prototypes consists of beam with continuous U-bars as reinforcement (Fig. 6) while the second set of prototypes consists of beam reinforcement which was anchored into the column for monolithic specimen and the lapping of reinforcement at joints for precast specimen was achieved by welding (Fig. 7).

From the lab tests, it was concluded that when comparing the two monolithic specimens, the specimen with U-bars reinforcement performed poorly than the monolithic specimen with beam reinforcement being anchored into the column. This had proven that adequate anchorage is important in increasing the capability and strength of the joint. Meanwhile, comparison between the precast specimen and the monolithic specimen had shown that the Precast Specimen 2 performed better than the others due to the welding at reinforcement lapping which increased the joint reinforcement. Precast Specimen 1 performed the least satisfactory, where sliding of beam end at the column interface due to inadequate continuity of joint reinforcements. However, the U-bar reinforcement anchorage owns higher ductility compared to conventional regular hooks (Megget, 2003).

Dywidag ductile connector ${ }^{\circledR}$ : Dywidag Systems International (DSI) produced a type of connector assembly namely Dywidag Ductile Connector ${ }^{\circledR}$ (DDC) owing thanks to Englekirk and Nakaki, Inc. who instigated the development of a completely different connector than the conventional design (Englekirk, 1996). Tested in 1993 at the University of California at San Diego, the DDC system performed well in overcoming failure even after sustaining more than 25 cycles of large displacement-controlled cyclic loadings with maximum storey drifts of $4.5 \%$. The single connection alone is able to withstand a reversible tensile force up to $1254 \mathrm{kN}$.

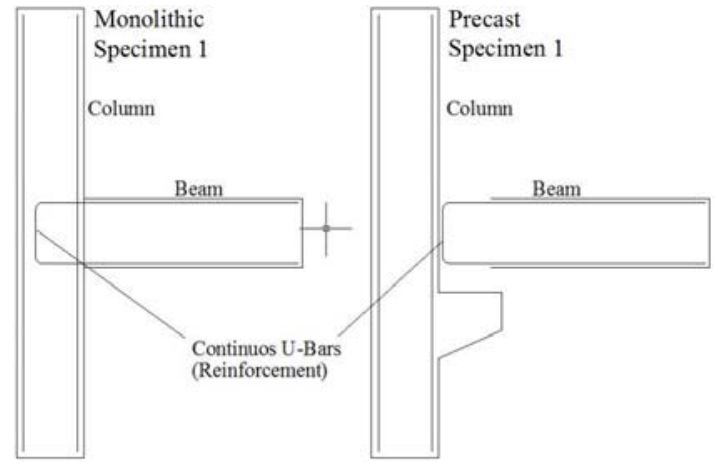

Fig. 6: Simplified figure of geometry and reinforcement of lab test specimen type 1

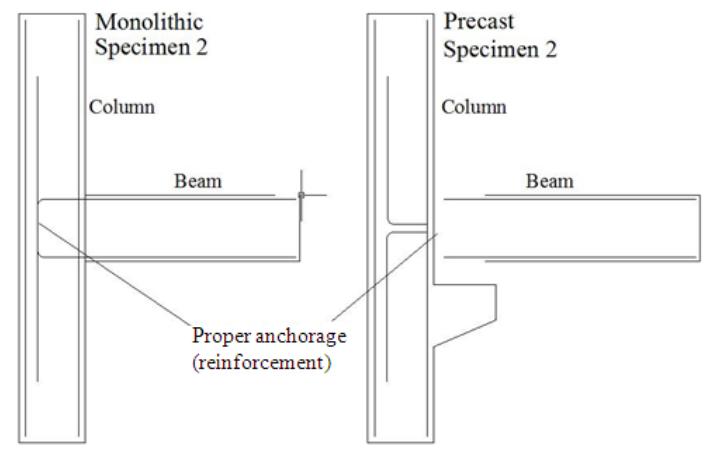

Fig. 7: Simplified figure of geometry and reinforcement of lab test specimen type 2

The DDC is basically a type of bolting connection connecting the precast beam to the precast column but at the same time increasing the seismic performance of the structure. This is achieved by using a very high quality steel rod with controlled post-elastic properties which will act as a "capacitor" that limits the loads to the balance of the system. It is designed and manufactured in the way that all post-elastic behaviors are confined to occur within the rod itself and this protects the jointed beam and column from damages due to earthquake distortions or deformations. Compared to the cast-in-situ ductile frame joints, the load path for earthquake deformations and energy absorptions must occur within the beam. According to Englekirk (Englekirk, 1996), the post-yield performance of concrete frame beams are improved by separation of the shear transfer mechanism from the inelastic behavior region. Further details of such system can be found in Englekirk (Englekirk, 2003).

\section{CONCLUSION}

Precast concrete constructions had demonstrated construction benefits such as shortening construction 
period, cutting down of construction costs, producing better quality of concrete products and creating more artistic structural shapes over the conventional cast-inplace method. With more and more large structures being put in place by using precast concrete components, it is significant that the IBS will be soon be overriding the conventional construction practices. With the increasingly demand in precast concrete construction, it is vital for us to learn and know the standing of the products being used and promoted especially in providing adequate earthquake resistance. Figure 8 and 9 shows the typical corbel connection used in the country for low-rise building erections.

Numerous researches, studies, experiments and investigations which had being carried out throughout the years to understand the seismic behaviors and performances of precast concrete frame systems had contributed to the development of new design guidelines and recommendations for the precast jointing systems. Most importantly, the existing but older version of code provisions was updated. Together with it, several types of precast concrete beam-column joints were developed as well. For instance, the hybrid post-tensioned precast concrete frame systems developed in the third phase of PRESSS research program were then being upgraded and further improved by other researchers. Therefore, precast concrete structures which used to be regarded as "house of cards (Englekirk, 1996)" are now the most likely buildings that are capable of surviving disastrous and severe earthquakes without excessive damage towards the structural components, compared to comparable cast-in-situ concrete constructions as well as steel structural systems.

Based on the past experimental analysis and lab investigations discussed in this study, it is obvious that there exist some common principles among all the developed connectors. In order to provide adequate seismic resistance, the connection between the beam and column of the ductile frame must be jointed with at least by using mild strength of steel bars, be it either as normal reinforcement, anchorage lapping or advanced post-tensioning elastic strands. The grouting with mortar alone does not help much in providing lateral dynamic restraining force of the structural frame. From the very basic type of normal cast-in-situ reinforcement joints to the very advanced and complicated hybrid system, they all reflect the needs and vitality that some modifications must be done in order to provide adequate seismic resistance. Therefore, the capability of a precast structure should not be taken for granted. A satisfactory seismic resistant precast joint must be able to fulfill the capacity of good energy dissipation, ductility, stiffness and ultimate strength.

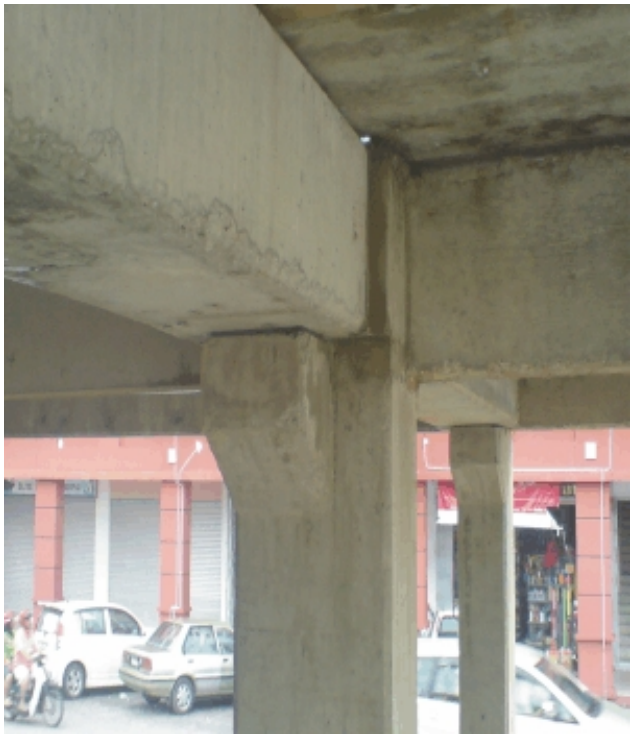

Fig. 8: Typical corbel beam-column connection in Malaysia

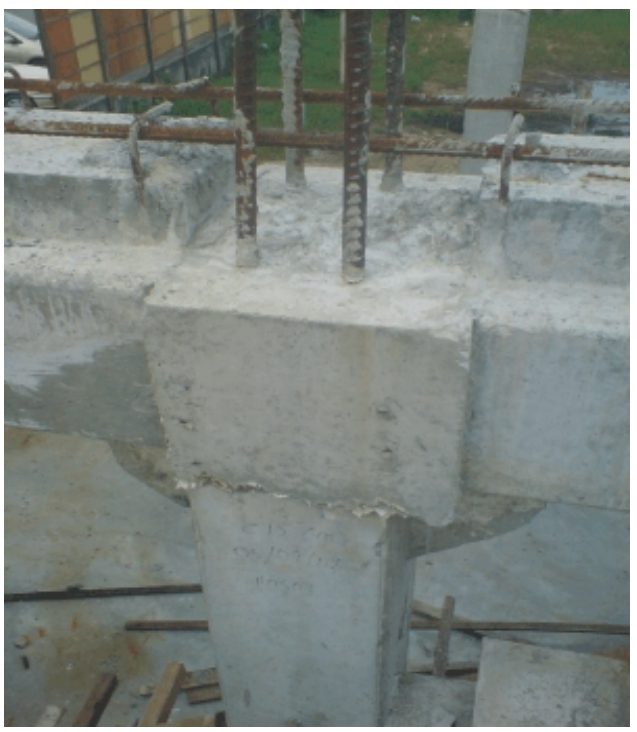

Fig. 9: Typical corbel beam-column connection in Malaysia

Among the discussed and presented types of joints for ductile precast concrete frame for earthquake resistant structure, the least recommended connection is through field welding as specified by Ozden and Ertas (2007) and Englekirk (1996). The main reason behind the unfavorable of welding is that field welding is often pricey and can create adverse results when the effects of welded regions are not thoroughly considered by the engineers, such as the additional forces caused by 
volume changes or eccentric temporary (or construction) loading (PCI Connection Details Committee, 2008). Therefore, unless careful considerations are given to the design and field work of welding, it is advisable to avoid choosing welding as the precast connection.

On the other hand, the Dywidag Ductile Connector ${ }^{\circledR}$ (DDC) is suggested the best connection in producing a ductile precast concrete frame for seismic loadings. Besides the technical strength and capability of the connection systems proven by lab tests, the system fulfils all the other important requirements of being a good connector; the capability to withstand large earthquake deformation; the capability to continue functioning even after vigorous earthquake events; straightforward installation process that does not require special knowledge and quality control precautions; and most importantly, the economical of the systems' cost. On top of that, the structural capacity of the connector is totally independent to the grouting of the gap between the beam and column or hardware accessories. In other words, this reduces the involvement of wet construction works throughout the erection of the whole structure.

As a matter of fact, most of these design procedures developed are catering for high seismic design factors, as most of the research teams contributing towards the research are from earthquake countries. It is essential for them to design for structures which are able to resist high seismic loadings. Meanwhile for non-earthquake country, it will be extravagant and uneconomical if the same code provisions are being referred to for seismic design practices.

The acceptance level of existing non-seismic resistant IBS construction technique among local contractors is reportedly low (Hassim et al., 2009), compared to many countries such as Germany, Singapore, Japan and United Kingdom. As mentioned in a case-study by Haron et al. (2005), majority of local contractors in Malaysia preferred the conventional building method over IBS due to higher cost issue faced in using prefabrication system. Needless to say, their perception towards IBS will undoubtedly become worse if implicated by stricter seismic resistance provisions. Therefore, there is a need for the development of more suitable precast concrete systems and a separate set of precast construction design guidelines to cater for low to moderate earthquake's intensity structural engineering. Importance of such local design codes and provisions review is clearly demonstrated in Musmar (2007). In developing new types of precast concrete joints for earthquake resistant frame, it should be bear in mind that the developed joints must not compromise the natural advantages of speedy and dry construction process of precast concrete erection itself.

\section{REFERENCES}

Begum, R.A., S.K. Satari and J.J. Pereira, 2010. Waste generation and recycling: Comparison of conventional and industrialized building systems. Am. J. Environ. Sci., 6: 383-388. DOI: 10.3844/ajessp.2010.383.388

David, J.D., 1987. Earthquake Resistant Design: for Engineers and Architects. 2nd Edn., John Wiley and Sons, New York, ISBN: 0471915033, pp: 519.

Ebrahimi, M., H. Sharifian and M. Ahangar, 2010. Seismic response evaluation of moment resistant frame with built-up column section. Am. J. Eng. Applied Sci., $\quad 3: \quad 37-41 . \quad$ DOI: 10.3844/ajeassp.2010.37.41

Elliot, K.S., G. Davies, H. Gorgun and M.R. Adlparvar, 1998. The stability of precast concrete skeletal structure. PCI J., 43: 42-57.

Englekirk, R.E., 1996. An innovative design solution for precast prestressed concrete buildings in high seismic zones. PCI J., 41: 44-53.

Englekirk, R.E., 2003. Seismic Design of Reinforced and Precast Concrete Buildings. 1st Edn, John Wiley and Sons, New Jersey, ISBN-10: 0471081221, pp: 848.

Gerald, A.E., 1998. Design-erection of B.C. rail yard control tower. PCI J., 43: 30-37.

Ghosh, S.K., 2001. Observations from the Bhuj Earthquake of January 26, 2001. PCI J., 46: 34-42.

Glover, C.W., 1964. Structural Precast Concrete. 1st Edn., CR Books Limited, London, pp: 664.

Haron, N.A., I.S. Hassim, M.R.A. Kadir and M.S. Jaafar, 2005. Building cost comparison between conventional and formwork system: A case study of four-storey school buildings in Malaysia. Am. J. Applied Sci., 2: $\quad$ 819-823. DOI: 10.3844/ajassp.2005.819.823

Hassim, S., M.S. Jaafar and S.A.A.H. Sazalli, 2009. The contractor perception towers industrialised building system risk in construction projects in Malaysia. Am. J. Applied Sci., 6: 937-942. DOI: 10.3844/ajassp.2009.937.942

Manoj, K.J., C.V.R. Murty and M.P. Jaisingh, 2005. Cyclic behavior of precast RC connections. Indian Connection. Indian Concreta J., 50: 43-50.

Megally, S., F. Seible, M. Garg and R.K. Dowell, 2002. Seismic performance of precast segmental bridge superstructures with internally bonded prestressing tendons. PCI J., 47: 2-18. 
Megget, L.M., 2003. The seismic design and performance of reinforced concrete beam-column knee joints in buildings. Earthquake Spectra, 19: 863-895. DOI: 10.1193/1.1623782

Musmar, M.A., 2007. A comparison between the new and the old versions of Jordan seismic code. Am. J. Applied Sci., 4: 229-232. DOI: 10.3844/ajeassp.2010.37.41

Ozden, S. and O. Ertas, 2007. Behavior of unbonded, post-tensioned, precast concrete connections with different percentages of mild steel reinforcement. PCI J., 52: 32-44.

PCI Connection Details Committee, 2008. PCI Connections Manual for Precast and Prestressed Concrete Construction. 1st Edn., Precast/Prestressed Concrete Institute, USA., http://www.wocbookstore.com/w-pci68.html

Priestley, M.J.N., S. Sritharan, J.R. Conley and S. Pampanin, 1999. Preliminary results and conclusions from the PRESSS five-story precast concrete test building. PCI J., 44: 42-67.
Sadrnejad, S.A. and M. Labibzadeh, 2006. Dynamic solution code for structural analysis upon joint element. J. Comput. Sci., 2: 401-409. DOI: 10.3844/jcssp.2006.401.409

Suyamburaja, A. and K. Subramanian, 2008. Experimental Investigation on three dimensional $\mathrm{RC}$ infilled frame-RC plane frame interactions with slab for seismic resistance. Am. J. Applied Sci., 5: 328-333. DOI: 10.3844/ajassp.2008.328.333

Suzanne, D.N., J.F. Stanton and S.R. Sritharan, 1999. An overview of the PRESSS five-story precast test building. PCI J., 44: 26-39.

Vasconez, R.M., A.E. Naaman and J.K. Wight, 1998. Behavior of HPFRC connections for precast concrete frames under reversed cyclic loading. PCI J., 43: 58-71.

Yalciner, H. and A.A. Hedayat, 2010. Repairing and strengthening of an existing reinforced concrete building: A north cyprus perspective. Am. J. Eng. Applied Sci., 3: 109-116. DOI: 10.3844/ajeassp.2010.109.116

Zhenqiang, L. and C.R. Ramirez, 1998. Designconstruction of olmpyic stadium in Honduras. PCI J., 43: 20-29. 